\title{
Nutritional Composition and Development of Chinese Dwarf Cherry (Cerasus Humilis (Bge.) Sok.)
}

\author{
Suyi Fan ${ }^{1}$, Peng Wu ${ }^{1,}$, , Gang Xing ${ }^{2}$ \\ ${ }^{1}$ Department of Food Processing and Safety, Food Science and Engineering, Shandong Agricultural University, Taian, China \\ ${ }^{2}$ Executive Office, Shandong Gaikang Biological Engineering Co. LTD, Taian, China
}

Email address:

wupengguai@163.com (Peng Wu)

${ }^{*}$ Corresponding author

\section{To cite this article:}

Suyi Fan, Peng Wu, Gang Xing. Nutritional Composition and Development of Chinese Dwarf Cherry (Cerasus Humilis (Bge.) Sok.). International Journal of Nutrition and Food Sciences. Vol. 8, No. 2, 2019, pp. 30-35. doi: 10.11648/j.jpnfs.20190802.11

Received: May 15, 2019; Accepted: July 2, 2019; Published: July 13, 2019

\begin{abstract}
Chinese dwarf cherry (Cerasus humilis (Bge.) Sok.), a typical representative medicine dual-purpose fruit type, is a health-care fruit proper to China. The fruit of Chinese dwarf cherry has unique flavor, rich nutrition and significant health care value. Its flowers, fruits, leaves and kernels also have certain value. The kernels can be used as raw material of the traditional Chinese herbal medicine Yu Liren, which has a medicinal history of more than 2000 years, and the flower, fruit, leaf and kernel can be comprehensively utilized. On the basis of summarizing the relevant research results, this paper firstly expounded the biological characteristics of Chinese dwarf cherry from the aspect of plant morphology of it. Secondly, from aspects of minerals, vitamins, amino acids, polyphenols, fatty acids and aromatic substances contained in Chinese dwarf cherry, the nutrients contained in Chinese dwarf cherry and its medicinal and medical care values were summarized. This paper summarized the progress of processing and application of fruit and kernel of Chinese dwarf cherry, and expounded the types and processes of products that were currently processed with fruit and kernel of Chinese dwarf cherry. This paper also summarized the problems existing in the research of Chinese dwarf cherry in the research and development, and prospected the development trend of Chinese dwarf cherry in processing and application, in order to provide a theoretical reference for the subsequent research.
\end{abstract}

Keywords: Chinese Dwarf Cherry, Composition, Development

\section{Introduction}

Cerasus humilis (Bge.) Sak., a genus of cherry of the family Rosaceae, is a multi-functional fruit tree that integrates nutrition and health care [1]. It is a unique fruit tree variety in China. It is mainly distributed in North China, Northwest China, Northeast China and other places in China. It is long in mountainous hills and has the characteristics of cold resistance, drought resistance and salt and alkali resistance [2]. Its plant is short, large in fruit and rich in nutrients. It has a variety of uses such as beautifying the environment, controlling sand and soil, and health care.

China's studies on Chinese dwarf cherry began in the early 1980s. The vitamins, minerals and other nutrients in the fruit are very rich [3], especially the calcium content is much higher than other fruits. According to the determination, the mass fraction of calcium in Chinese dwarf cherry is $524 \mathrm{mg} \cdot \mathrm{kg}^{-1}$, and the mass fraction of calcium in fresh kernels is 3743 $\mathrm{mg} \cdot \mathrm{kg}^{-1}$, hence the name 'Calcium Fruit'. Chinese dwarf cherry is a typical representative medicine dual-purpose fruit type, and is a health-care fruit which is also known as the green 'natural calcium powder' [4-5].

This paper mainly summarizes the research progress and health value of Chinese dwarf cherry's nutrient composition, and prospects its development and utilization prospects, aiming to provide scientific theoretical basis for Chinese dwarf cherry's nutritional value and further development and utilization.

\section{Biological Characteristics of Chinese Dwarf Cherry}

Chinese dwarf cherry's general plant height is $0.8 \sim 1.5 \mathrm{~m}$, while the crown diameter during $1 \sim 1.5 \mathrm{~m}$, and its budding power is very strong. It has many branches, and the plant 
cluster covers about $0.2 \sim 0.5 \mathrm{~m}^{2}$. The leaf of Chinese dwarf cherry has a length of about $5 \mathrm{~cm}$ and a width of about $1.4 \mathrm{~cm}$ with oblong and lanceolate shape. The flowers are often white, or with light pink, and about $1.5 \mathrm{~cm}$ in diameter. The flowering period is from late April to early May, which makes Chinese dwarf cherry beautiful and has ornamental value. The fruit is approximately spherical, oblate or oblong, $1.5 \sim 2.5 \mathrm{~cm}$ in diameter, with color of purplish red, bright red or yellow, and its flesh is red or reddish, shaped like cherry, with unique and sour taste like plum [6-8].

\section{Nutritional and Medicinal Value of Chinese Dwarf Cherry}

There are many studies on nutrients in Chinese dwarf cherry fruit, and mainly focus on minerals, vitamins, amino acids, polyphenols, fatty acids and aromatic substances [9-11].

Table 1. Nutrients in various types of fruits.

\begin{tabular}{llllll}
\hline Nutrients & Cerasus humilis & Apple & Strawberry & Grape & Cherry \\
\hline $\mathrm{Ca}$ & $524.0 \mathrm{mg} / \mathrm{kg}$ & $24.4 \mathrm{mg} / \mathrm{kg}$ & $180.0 \mathrm{mg} / \mathrm{kg}$ & $110.0 \mathrm{mg} / \mathrm{kg}$ & $83.8 \mathrm{mg} / \mathrm{kg}$ \\
$\mathrm{Fe}$ & $109.1 \mathrm{mg} / \mathrm{kg}$ & $6.2 \mathrm{mg} / \mathrm{kg}$ & $18.0 \mathrm{mg} / \mathrm{kg}$ & $2.0 \mathrm{mg} / \mathrm{kg}$ & $9.1 \mathrm{mg} / \mathrm{kg}$ \\
$\mathrm{Zn}$ & $5.8 \mathrm{mg} / \mathrm{kg}$ & $0.2 \mathrm{mg} / \mathrm{kg}$ & $1.4 \mathrm{mg} / \mathrm{kg}$ & $0.2 \mathrm{mg} / \mathrm{kg}$ & $1.5 \mathrm{mg} / \mathrm{kg}$ \\
$\mathrm{VC}$ & $590.1 \mathrm{mg} / \mathrm{kg}$ & $73.2 \mathrm{mg} / \mathrm{kg}$ & $470.0 \mathrm{mg} / \mathrm{kg}$ & $40.0 \mathrm{mg} / \mathrm{kg}$ & $110.0 \mathrm{mg} / \mathrm{kg}$ \\
\hline
\end{tabular}

\subsection{Minerals}

Minerals cannot be synthesized by the human body. Although they cannot provide energy, they play an important physiological function in human tissues and must be supplemented from the external environment. Minerals are divided into two major categories: macroelements (phosphorus, sulfur, potassium, calcium, magnesium, etc.) and trace elements (copper, iron, zinc, manganese, etc.). The order of the major elements in the fruit of Chinese dwarf cherry is $\mathrm{K}>\mathrm{Ca}>\mathrm{P}>\mathrm{S}$, and the order of trace elements is $\mathrm{Fe}>\mathrm{Zn}>\mathrm{Mn}>\mathrm{Cu}$. Compared with other fruits, the average content of $\mathrm{K}$ in Chinese dwarf cherry was higher than that of the grape and lower than that of the strawberry; the average content of $\mathrm{Ca}, \mathrm{Fe}$ and $\mathrm{Zn}$ was significantly higher than that of grapes, cherry, strawberry and apple [12-16]. The calcium content in Chinese dwarf cherry is extremely high. The mass fraction of calcium in the pulp is up to $524 \mathrm{mg} / \mathrm{kg}$, and the mass fraction of calcium in the fresh kernel is up to 3743 $\mathrm{mg} / \mathrm{kg}$ [17]. The calcium nutrient elements in Chinese dwarf cherry are mainly water-soluble calcium and calcium phosphate, which are easy to absorb and suitable for calcium supplementation in children, middle-aged and elderly people [18].

\subsection{Vitamins}

Many animals can synthesize VC in the body, but humans need to get it from food. Pulp of Chinese dwarf cherry contains vitamins such as VA, VB1, VB2, VB6, VB12, VC, $\mathrm{VE}$, etc., and the mass fraction of $\mathrm{VC}$ is $590.1 \mathrm{mg} / \mathrm{kg}$, which is much higher than that of other fruits such as apple, grape and strawberry [12-16]. Detailed data is shown in Table 1.

\subsection{Amino Acid}

Pulp of Chinese dwarf cherry is rich in a variety of essential amino acids. High performance liquid chromatography-mass spectrometry (LC-MS/MS) isotope internal standard method was used to determine the amino acids in Chinese dwarf cherry juice. The results showed that Chinese dwarf cherry juice contains 19 kinds of amino acids, 7 kinds of essential amino acid. Amino acid analyzer was also used to analyze the amino acids in Chinese dwarf cherry. The results showed that the amino acids in Chinese dwarf cherry fruit were complete and the total content was $354.98 \mathrm{mg} / 100 \mathrm{~g}$, among which the content of aspartic acid was the highest. The content of glutamic acid, proline, leucine, lysine and proline was less than that of aspartic acid, and the content of threonine and methionine was the lowest [19]. Among the amino acids contained, the essential amino acid content is as high as $118.42 \mathrm{mg} / 100 \mathrm{~g}$. Lysine, leucine, isoleucine and proline are essential amino acids in children, and the content is relatively high. Therefore, from the aspect of amino acid content, Chinese dwarf cherry is also a kind of nutritious fruit for children. It is very nutritious and can eliminate fatigue, promote growth, resist aging and improve the body's immunity. At the same time, drought-tolerant plants have higher proline content [20], and the proline content in Chinese dwarf cherry is also higher than that of common plants, which is supposed to be a physiological reason for its drought resistance, which needs further research.

\subsection{Polyphenols}

At present, the forint-phenol colorimetric method has been applied to the determination of polyphenol content in Chinese dwarf cherry [21]. This method is stable and reliable, and can provide a basis for the determination of polyphenol content in it. The polyphenol content in different parts of Chinese dwarf cherry has significant differences, and the pericarp contains the highest polyphenol content [22]. Polyphenols have the effect of resisting oxidation, strengthening blood vessel walls, promoting digestion of the stomach and strengthening the body's resistance, and are known as "the seventh type of nutrients." Cheng used three different evaluation systems to detect the scavenging free radicals and antioxidant activities of oligophenols. It was found that polyphenol can inhibit free radical-induced oxidative damage of biofilm, lipoprotein and serum albumin by quenching free radicals [22]. The research 
and development of polyphenol content in Chinese dwarf cherry in processing applications remains to be further explored.

\subsection{Fatty Acids}

Liu et al. detected 31 fatty acids in Chinese dwarf cherry, more than olive oil and sea buckthorn oil [23]. Among them are 20 kinds of saturated fatty acids, and mainly palmitic acid, wood taric acid and stearic acid; 11 kinds of unsaturated fatty acids, mainly oleic acid, linoleic acid and linolenic acid, and the first detection of nervonic acid [24]. Nervonic acid is an important component of brain nerve cells and an essential nutrient for the growth and development of brain cells, optic nerve cells and peripheral nerve cells. It plays an important role in maintaining the activity of cranial nerves, preventing the decline of brain nerve function and treating Parkinson's dementia.

\subsection{Aromatic Substances}

The aroma of Chinese dwarf cherry is rich and pleasant. Three kinds of maturity "Jingou II" were detected by headspace solid phase micro-extraction combined with gas chromatography-mass spectrometry, and a total of 75 aroma components were detected [25]. Recent studies have shown that the volatile oil components of plants have a variety of biological effects. They can eliminate human fatigue, enhance immunity and promote physical and mental health, and have a variety of microbial resistance, and can be good antibacterial, insecticidal, antiseptic plant material. They also have anti-oxidation properties, which can effectively remove free radicals in the body, reduce free radical damage to organisms, inhibit multiple mutations, reduce toxicity, protect liver, prevent diabetes, reduce blood lipids and other biological activities, and will be widely used in medical research, food industry and chemical industry [26].

\subsection{Kernel oil of Chinese Dwarf Cherry}

Kernels of Chinese dwarf cherry contain $46 \% \sim 74 \%$ of oil, while the unsaturated fatty acid content of it is more than $90 \%$. The composition is very similar to olive oil, and contains bioactive substances such as VE, VA, squalene and sterol. Five major fatty acids of palmitic acid, palmitoleic acid, stearic acid, oleic acid and linoleic acid were detected by gas chromatography, with the highest content among them being oleic acid and linoleic acid [27]. Kernel oil of Chinese dwarf cherry has a certain scavenging effect on free radicals, as well as good antioxidant activity and strong antioxidant capacity to liver tissues. It is a high quality natural oil with great potential in the application of food and its additives and cosmetics industry [28-29].

\subsection{Amygdalin}

Amygdalin is an effective component of Chinese traditional medicine bitter almond. It has antitussive and antiasthmatic effects, which can improve digestive system, anti-inflammatory, anti-tumor, anti-oxidation and delay the degeneration of intervertebral disc [30-32]. Chinese dwarf cherry kernel contains a large amount of amygdalin, and Xiao et al. determined the content of bitter almond in the concentrate of Chinese dwarf cherry kernel by HPLC and explored its anti-oxidation. The results showed that the concentration of amygdalin in the extract was $7.94 \mathrm{mg} / \mathrm{mL}$, and the ability of amygdalin to scavenge DPPH decreased with the decrease of its concentration [33]. At present, it is common to extract amygdalin by traditional methods such as water extraction, and no research on new extraction methods has been found. Moreover, it is easy to extract similar substances when extracting amygdalin, and whether these substances have an effect on the action of amygdalin remains to be studied [34].

\section{Processing of Chinese Dwarf Cherry}

Chinese dwarf cherry belongs to the stone fruit category and has the characteristics of being incapable of storage and transportation. Moreover, the content of organic acids and phenols in Chinese dwarf cherry is higher and the sugar content is less, so the taste is sour. However, it has a strong aroma, and the color is still stable and does not have a cooking taste after heat treatment, which is suitable for eating after processing [35-36]. Therefore, many scholars have started a lot of research from the perspective of deep processing.

\subsection{Flesh of Chinese Dwarf Cherry}

Flesh of Chinese dwarf cherry can be processed into juice, fruit wine, sugar products, fruit vinegar and other processed products. The product has unique flavor and rich nutritional value.

In terms of juice making, research on extraction [37] and pressing [38] methods and corresponding patents have been made. Pectinase is added in both methods to improve the juice yield and the clarity of the juice. The production process of Chinese dwarf cherry flesh drink and fermented milk drinks containing Chinese dwarf cherry has also been researched and developed [39]. Its products are bright in color, rich in aroma, unique in flavor, and able to maintain the total calcium and other nutrients of Chinese dwarf cherry.

In the process of making oysters and sauces, the processing technology of no-sulfur and low-sugar preserved Prunus humilis has also been studied, and the obtained products are full and transparent, soft and elastic [40].

In addition, there are products such as jam and fruit leather [41]. Chinese dwarf cherry pulp is extremely rich in nutrients, so all flesh should be fully utilized. The opaque jam allows all the flesh to be used, but the turbidity of the sauce is unattractive; the transparent jam is rosy and pleasing to the eye, but it loses some of the nutrients. Therefore, Tian et al. developed series of transparent jam with transparent fruit pieces with rose color suspending therein [42]. The delicate appearance of the fruit pieces is flexible and realizes the full utilization of the pulp. 
In terms of wine making, fruit wine is usually brewed by pomace fermentation [43] (refer to the red wine brewing process) and fermentation after the juice is obtained [44-46] (refer to white wine).

In the aspect of vinegar, there has been research on the processing of vinegar and acetic acid beverages [47-49]. The above studies all adopt the liquid fermentation process, and the yeast species such as French active dry yeast, ICV active dry yeast and the acetic acid strains such as AS1141 acetic acid strain are selected, and the fruit vinegar is made into an acetic acid beverage by adjusting sugar, adjusting acid and coloring.

\subsection{Kernel of Chinese Dwarf Cherry}

Although the kernel of Chinese dwarf cherry only accounts for about $6 \%$ of the total weight of its fruit, it still has very important value.

First of all, it can be used as medicine with antitussive and antispasmodic effects. Secondly, it is rich in kernel protein, with an extraction rate of $56 \%$. Its amino acid composition is similar to that of soy protein and peanut protein, and its nutritional value is extremely high, which can be applied to many aspects [50]. In addition, domestic research has shown that the oil content of Chinese dwarf cherry kernels is as high as $50 \%$, and the content of unsaturated fatty acids in the oil is as high as $90 \%$ [51]. It also contains bioactive substances such as VE, VA, squalene and sterol, which is suitable as a bioactive substance. Raw materials for nutritional supplements. Kernel of Chinese dwarf cherry also contains a large amount of amygdalin, a kind of cyanogenic glycosides, which has the characteristics of analgesic, cough and anti-inflammatory. However, it will decompose in the presence of enzyme of amygdalin and produce benzaldehyde, glucose and hydrocyanic acid, which is highly toxic. The LD50 of oral amygdalin is $60 \mathrm{mg} / \mathrm{kg}$, and a large amount of bitter almonds may cause poisoning or even death [52]. Therefore, in the storage process of Chinese dwarf cherry kernel, the water activity should be controlled at 0.67 to prevent the decomposition of amygdalin under the action of enzyme. While extracting amygdalin, it is necessary to treat the kernel with high temperature to inactivate enzyme and protect amygdalin [53].

\section{Problems in the Study of Chinese Dwarf Cherry}

Nowadays, Chinese dwarf cherry is increasingly valued for its outstanding cold resistance, drought resistance, salt and alkali resistance, environmental adaptability, high nutrition and health care value. It will gradually become a hot spot for research, processing and utilization. However, the following problems still exist in its research and development.

1) In the past, due to the lack of research on Chinese dwarf cherry, especially the lack of understanding of its nutrition and health functions, few people have introduced and cultivated Chinese dwarf cherry. At present, there is still no large-scale cultivation [54]. The research only stays in resource surveys and small-area trials.

2) Kernel of Chinese dwarf cherry is the main source of semen pruni, and its germplasm resources evaluation, pharmacological effects and composition need further research.

3) The comprehensive utilization of Chinese dwarf cherry is not enough, and there are few products using flowers, leaves and rhizome as the main raw materials.

\section{Application Prospects}

Germplasm resources of Chinese dwarf cherry are very rich, and reasonable economic development can bring huge economic, ecological and social benefits.

With the development of nutrition disciplines and health-care functional foods and changes in dietary structure, people are paying more and more attention to their own diet health, especially for natural nutrient-rich and pollution-free wild fruits, showing great enthusiasm and preference. Comprehensive development and utilization of Chinese dwarf cherry's stems and leaves, flowers, fruits and kernels can broaden the market of Chinese dwarf cherry and enhance the nutritional value and diversity of products, which is an important way for the industrialization of Chinese dwarf cherry.

Chinese dwarf cherry has the effect of conserving water sources and preventing soil erosion. Vigorously promoting the cultivation of Chinese dwarf cherry has an important role in improving the ecological environment and promoting the sustainable development of agriculture in the Chinese dwarf cherry planting area, and will gradually become one of the directions for Chinese dwarf cherry's future research and development.

Chinese dwarf cherry has been in a wild state for a long time. With the fruit of blueberry and other functional fruits entering people's field of vision, Chinese dwarf cherry's research has also received more and more attention. Chinese dwarf cherry's research and development needs to cooperate with many industries such as agriculture, forestry, medicine, chemistry and food, thus strengthening the links between disciplines and promoting the development of the industry.

\section{Conclusion}

Chinese dwarf cherry is a fruit tree with abundant resources. It has rich nutrients and high edible and medicinal value. It is of far-reaching significance to carry out in-depth research on the processing and utilization of various parts of the plant. Nowadays, with the improvement of living standards, people pay more and more attention to the function and health of diet. However, the research on the nutrition and health functions of Chinese dwarf cherry is still lacking, such as the extraction, processing and utilization of nervonic acid and amygdalin in Chinese dwarf cherry. If we conduct in-depth research on these aspects, it will play an important role in the development of Chinese dwarf cherry and the diversification of the food 
industry. In general, the development prospects of Chinese dwarf cherry has great potential.

\section{References}

[1] Mo C, Li W D, He Y X, et al. Variability in the sugar and organic acid composition of the fruit of 57 genotypes of Chinese dwarf cherry [Cerasus humilis (Bge.) Sok] [J]. Journal of Pomology \& Horticultural Science, 2015, 90 (4): 419-426.

[2] Song X S, Shang Z W, Yin Z P, et al. Mechanism of xanthophyll-cycle-mediated photoprotection in Cerasus humilis, seedlings under water stress and subsequent recovery [J]. Photosynthetica, 2011, 49 (4): 523-530.

[3] Liu Y F, Wang Y X, Jia L. Exploring the value and mode of comprehensive development of Cerasus humilis from the perspective of national strategy [J]. Agriculture \& Technology, 2013, 33 (07): 114

[4] Li W D, Gu J R. Research Progress on Healthy Function and Pharmacological Effect in Cerasus humilis of Fruit Medicine Dual-purpose Type [J]. Modern Chinese Medicine, 2017, 19 (9): 1336-1340.

[5] Zhang Q, Song J Y, Shao F, et al. Potential suitable distribution area and ecological characteristics of Cerasus humilis, an excellent tree species for windproof and sand fixation [J]. Journal of Beijing Forestry University, 2018, 40 (03): 66-74.

[6] Liu Z G, Hao F. Cerasus humilis and its development prospects [J]. Forest Science and Technology, 2005 (3): 44-44.

[7] Zhang M L, Deng Q C, Yang C X, et al. Study on Nutrition Components from Fresh Fruit and Pip of Inner Mongolia Cerasus humilis (Bge.) Sok. [J]. Amino Acids \& Biotic Resources, 2007, 29 (4): 18-20.

[8] Sun M, Zhang Y L. Cultivation technology of Cerasus humilis [J]. Northern Fruits, 2004 (S1): 83-84.

[9] Cao H Q, Liu S Y, Wang G Y, et al. Nutritional Composition and Development of Prunus Humilis Bunge [J]. Farm Products Processing, 2015 (24): 70-72.

[10] Du Y F, Liang H Q, Zhu Y M, et al. The Determination Analysis of Calcium, Iron, Zinc and Selenium Content in Fruits and the Ecological Adaptability of Chinese Dwarf Cherry in XinJiang [J]. Xinjiang Agricultural Sciences, 2012, 49 (12): 2202-2207.

[11] Li W D, Li O, He Y X, et al. Analysis of Nutrient Element Characteristics of Flesh of Chinese Dwarf Cherry Based on Total Reflection X-Ray Fluorescence Method [J]. Food Science, 2015, 36 (4): 164-167.

[12] Zhang X Y, Chen X S, Peng Y, et al. Genetic Diversity of Mineral Elements, Sugar and Acid Components in Malussieversii (Ldb.) Roem [J]. Acta Horticulturae Sinica, 2008, 35 (2): 277-280.

[13] Luo X B, He L M. Nutritional Value and Health Function of Strawberry [J]. Food and Nutrition in China, 2011, 17 (4): 74-76.

[14] Wang C T. Nutritional value and cultivation techniques of grapes [J]. Chinese Horticulture Abstracts, 2012, 28 (09): 159-160.
[15] Cui X Y, Li X Y, Kong X Y, et al. On the Effective Components of Tart Cherry (Prunus cerasus L) and Their Pharmacological Effects [J]. Journal of Beihua University (Natural Science), 2007, 8 (2): 145-149.

[16] Shen Y. Study on Nutritional Components and Anthocyanins of Cherry Fruit [D]. Nanjing Forestry University, 2014.

[17] Li W D, Li O, Mo C, et al. Mineral element composition of 27 Chinese dwarf cherry (Cerasus humilis (Bge.) Sok.) genotypes collected in China [J]. Journal of Pomology \& Horticultural Science, 2014, 89 (6): 674-678.

[18] Liu H R, Du B, Ren Y J, et al. Composition of Calcium and Its Change During Storage in Prunus humilis Fruits [J]. Acta Nutrimenta Sinica, 2011, 33 (4): 421-422.

[19] Li X L. Determination and Analysis of Nutritional Content in Prunus humilis [J]. Journal of Agriculture, 2015, 5 (8): 97-100.

[20] Li W, Li O, Zhang A, et al. Genotypic diversity of phenolic compounds and antioxidant capacity of Chinese dwarf cherry (Cerasus humilis, (Bge.) Sok.) in China [J]. Scientia Horticulturae, 2014, 175 (1): 208-213.

[21] Cai Y H, Wang X M, Zhao K. Establishment of Folin-Ciocalteu Colorimetric for Determining Cerasus humilis Polyphenol [J]. The Food Industry, 2014, 35 (06): 277-279.

[22] Li O, Li W D, Hu X, et al. Difference Comparison of Content of Polyphenol from Fruit of Cerasus humilis [J]. Chinese Journal of Experimental Traditional Medical Formulae, 2012, 18 (22): 53-56.

[23] Yue H, Zhang Y X, Chen F R, et al. Analysis of fatty acids in olive oil and sea buckthorn oil by GC-MS [J]. West China Journal of Pharmaceutical Sciences, 2016, 31 (5): 521-523.

[24] Liu J Y, Zhang H C, Wei Q, et al. Determination on Fatty Acids of Chinese Dwarf Cherry by GC-MS and Analysis on Nutritional Value [J]. Food Research and Development, 2012, 33 (9): 119-123.

[25] Liu J Y, Li S S, Yan Z, et al. Effect of Harvest Maturity on Aroma Components of Chinese Dwarf Cherry with GC-MS [J]. Food Research and Development, 2018, 39 (14): 148-152.

[26] Dorman H J, Deans S G. Antimicrobial agents from plants: antibacterial activity of plant volatile oils. [J]. Journal of Applied Microbiology, 2010, 88 (2): 308-316.

[27] Mu X P, Du J J, Du J M. Extraction and composition analysis on the fatty acids in the kernel of Chinese Dwarf cherry [J]. Food Science and Technology, 2012, 37 (12): 140-143.

[28] Lin H. Study on antioxidation activities of Chinese dwarf cherry seed oil [J]. Science and Technology of Food Industry, 2012, 33 (15): 105-107.

[29] Xu L K, Fang L, Ge X Y. Effects of Ophiopogon japonicus seed oil on antioxidant activity of liver in rats after exhaustive exercise [J]. China Oils and Fats, 2018, 43 (01): 64-66+88.

[30] Xing G X, Li N, Yang M Y, et al. Research progress on natural amygdalin [J]. Chinese Traditional Patent Medicine, 2003, 25 (12): 1007-1009.

[31] Li L, Dai T, Li X L, et al. Advances in pharmacological studies of amygdalin [J]. Journal of Jilin Medical University, 2016, 37 (1): 63-66. 
[32] Lv J Z, Deng J G. Research progress in pharmacological effects of amygdalin [J]. Drugs \& Clinic, 2012, 27 (5): 530-535.

[33] Wu X Y, Sun Y X, He G, et al. Extracting and Anti-oxidative Activity of Amygdalin from Kernel of Prunus humilis Bunge [J]. Hubei Agricultural Sciences, 2013, 52 (19): 4764-4767.

[34] Wang B H, Zhang W H, Zhang X F, et al. New Research Progress on Extraction Process and Harmacological Effects of Amygdalin [J]. Chinese Archives of Traditional Chinese Medicine, 2014, 32 (02): 381-384.

[35] Gao S. Economic value and planting technology of Cerasus humilis [J]. Vocational Technology, 2006 (12): 195-195.

[36] Geng Y H, Xu K, Su S, et al. Evaluation of Cerasus humilis Fermented Feed and Its Effect on the Quality of Goat Milk [J]. Feed Research, 2017 (15): 31-36.

[37] Wang J, Yuan L, Wang X R. Cerasus humilis and processing method thereof: CN, CN 1935033 A [P]. 2007.

[38] Lan Y P, Zhou J H, Zhou L D, et al. Cerasus humilis juice beverage and preparation method thereof:, CN 100998433 A [P]. 2007.

[39] Liang Y H, Li F L, Dong C Y, et al. Development of Fermented Milk Drinks Containing Calcium Fruits [J]. Modern Food Science and Technology, 2006, 22 (2): 183-184.

[40] Zhou J H, Lan Y P, Yao Y W, et al. Studies on processing technology no-sulfur and low-sugar preserved Prunus humilis [J]. Food Science and Technology, 2007, 2007 (6): 151-153.

[41] Liang W Z, Song S M. Development of calcium fruit series sugar products [J]. China Fruit \& Vegetable, 2007 (6): 42-42.

[42] Tian J Q, Lan Y P, Wang Q, et al. Processing Technology of Series of Prunus Jam [J]. Academic Periodical of Farm Products Processing, 2011 (5): 43-44.

[43] Du Z J, Luo J H, Gao N F. Principium manufacture of prunus humilis bunge-ratafee [J]. China Brewing, 2006, 25 (7): 71-73.
[44] He W J, Han S Z, Qie Z M. Present Situation and Thinking of Brewing Fruit Wine by Cerasus humilis Juice [J]. Shanxi Fruits, 2007 (4): 34-35.

[45] Liu J H, Guo Y R. Study on the Fermentation Techniques of "Gaiguo" Fruit Wine [J]. Liquor-Making Science \& Technology, 2007 (2): 74-75.

[46] Zhou J H, Chang H, Lan Y P, et al. Study on brewing technology of Prunus humilis fruit wine $[\mathrm{J}]$. Science and Technology of Food Industry, 2010, 31 (01): 269-271.

[47] Xue J, Wang Y J, Chen X F. Brewing process of Cerasus Humilis acetic acid beverage [J]. Food and Fermentation Industries, 2005, 31 (12): 140-142.

[48] Pang J J, Hu Y F, Li X H, et al. Study on process of Cerasus Humilis vinegar [J]. Food Science and Technology, 2008, 33 (5): 54-57.

[49] Li X H, Pang J J, Hu Y F, et al. Material and process study of Cerasus Humilis Vinegar [J]. China Condiment, 2008, 33 (6): 33-36.

[50] Chen W, Wang Y H, Xue Y, et al. Studies on the Extraction and Properties of Protein from Cerasus Humilis Kernel [J]. Food Science, 2005, 26 (3): 138-141.

[51] Xue Y, Chen W, Cheng S, et al. Studies on Two-phase Solvent Extraction of Cerasus Humilis Oil [J]. Journal of Zhengzhou Grain College, 2003 (1): 20-23.

[52] Liu C, Cao Q M, Tu Y, et al. The Determination of Amygdalin and the Process of Removing the Bitterness in the Almond Skin [J]. Food Research and Development, 2015, 36 (03): 59-63.

[53] Tian J Q, Lan Y P, Zhu K R, et al. Key technology of multipurpose use of Cerasus humilis kernel [J]. China Oils and Fats, 2012, 37 (2): 65-69.

[54] Huang P. Research Review for Domestic Propagation Technology of Prunus humilis Bunge [J]. Heilongjiang Agricultural Sciences, 2016 (1): 166-169. 